\title{
A COLLABORATIVE APPROACH : THE RURAL FALLS INJURY PREVENTION PROGRAM
}

\section{Deborah Radvan}

Rural Falls Injury Prevention Program

Hunter Centre for Health Advancement

Health promotion workers from rural and regional areas often work in relative isolation. This article describes a program that provides these health promotion workers with an opportunity to come together to build the infrastructure and capacity required for sustainable change through health promoting programs.

Research suggests that one of the best ways to reduce the heavy burden of falls among older people is to increase the participation of older people in appropriate exercise and activities to improve their strength, balance, flexibility and mobility. ${ }^{1,2,3}$ One of the greatest challenges facing health workers in rural and regional NSW is to find ways to increase the access of older people to these activities.

To address this challenge, the Rural Falls Injury Prevention Program (RFIPP) has brought together 10 NSW area health services: Greater Murray, Hunter, Illawarra, Macquarie, Mid North Coast, Mid Western, New England, Northern Rivers, Southern and Wentworth. These area health services are collaborating on the RFIPP, which has been funded by the NSW Department of Health's Injury Prevention and Policy Unit and is being managed by the Hunter Centre for Health Advancement. A project team has been established to support the RFIPP.

The first objective of the program is to conduct a comprehensive audit of the opportunities that older people have to participate in appropriate exercise and activities. A telephone survey is being conducted by the ComputerAssisted Telephone Survey (CATI) facility within the Hunter Centre for Health Advancement. The survey targets a range of service providers in regional and rural areas, and aims to develop a profile of opportunities to increase access to exercise, and to identify barriers to service provision. The audit will provide data to facilitate the development of local action plans that will be implemented in 2002 .

This innovative collaborative model has several advantages. It allows for the sharing not only of resources, but of experience and insight as well. There will be a focus on organisational and workforce development, resource allocation, building partnerships, and local leadership.

For more information about the RFIPP, please contact Deborah Radvan on (02) 49246246 or by email at

deborah.radvan@hunter.health.nsw.gov.au.

\section{REFERENCES}

1. Lord S, Ward J, Williams P, and Strudwick M. The effect of a 12 month exercise trial on balance, strength and falls in older women: a randomised controlled trial. J Am Geriatr Soc 1995; 43: 1198-206.

2. Wolf S, Barnhart H, Kutner N, McNeely E, Xu T, and the Atlanta FICSIT Group. Reducing frailty and falls in older persons: an investigation of Tai Chi and computerised balance training. J Am Geriatr Soc 1996; 44: 489-97.

3. National Ageing Research Institute (NARI). An analysis of research on preventing falls and falls injury in older people: community, residential aged care and acute care settings. Canberra: Commonwealth Department of Health and Aged Care, 2000. 